\title{
The Layout of Beijing Quadrangle Courtyard and Views of Nature in Chinese Philosophy
}

\author{
Xingyu Zhao ${ }^{1, \mathrm{a}}$, Yongyi Wen ${ }^{2, \mathrm{~b}^{*}}$ \\ ${ }^{1}$ Department of Humanities and Management, Shaanxi University of Chinese Medicine, Qindu, Xianyang, Shaanxi, \\ China \\ 2 Department of Humanities and Management, Shaanxi University of Chinese Medicine, Qindu, Xianyang, Shaanxi, \\ China \\ azhao.xingy@qq.com \\ b*1121602719@qq.com
}

\begin{abstract}
Starting from the architectural layout of Beijing quadrangle courtyard, this paper makes a philosophical reflection on the relationship between man and nature contained in it, and discusses the embodiment of the concepts of Yin and Yang, cosmology and geomancy in Beijing quadrangle courtyard in ancient Chinese philosophy. It is believed that the architectural design of Beijing quadrangle courtyard is influenced by the natural view of ancient philosophy and enriches the content of it, which can be reflected by the architecture itself, so that can make it easier for future generations to understand the traditional Chinese ideology and culture and attach importance to the enlightening significance of tradition.
\end{abstract}

Keywords: Beijing quadrangle courtyard, conception of nature, yin and yang, cosmology, geomancy

\section{北京四合院布局与古代哲学自然观}

\author{
赵星宇 $1, \mathrm{a}$ 闻永毅 $2, \mathrm{~b}^{*}$
}

\author{
${ }^{1}$ 陕西中医药大学人文管理学院, 秦都, 咸阳, 陕西, 中国 \\ ${ }^{2}$ 陕西中医药大学人文管理学院，秦都，咸阳，陕西，中国 \\ azhao.xingy@qq.com \\ b*1121602719@qq.com
}

\section{摘要}

本文主要从北京四合院建筑布局出发, 对其中蕴涵的人与自然的关系哲学展开思考, 讨论了中国古代哲学自然 观中阴阳观、宇宙观和风水观念在北京四合院中的体现。认为北京四合院的建筑设计受到了古代哲学自然观的 影响, 同时丰富了中国古代哲学自然观的内容, 并通过建筑本身体现出来, 能够使后人更易于理解中国传统思 想文化，重视传统的启示意义。

关键词：北京四合院，自然观，阴阳，宇宙观，风水

\section{1. 前言}

人类最初在大地上活动时, 以天为被、以地为床, 几乎与自然融为一体, 但抵御不了自然的灾害。而后 为了遮风避雨, 在一定程度上躲避自然灾害, 人类从 需求出发开始建造住所, 这时建筑就处于人与自然之 间，成为人与自然交流的媒介。人类居住、活动的场 所从露天、洞穴、简易的天然材料所搭建的遮蔽物到
地面宫室的建立, 是人类对大地空间人为的安排和占 有。 ${ }^{[1]}$ 建筑是人造出来的自然物, 同时又是人躲避自 然灾难的手段和工具。人处在建筑之内, 就能躲避自 然灾难; 人离开建筑就进入了自然环境。然而人不可 能完全脱离自然, 建筑本身也处在自然之中, 人通过 建筑仍然可以和自然接触, 也受到自然的影响。建筑、 人与自然之间的关系可谓是密不可分。 
人们说“建筑是石头的史书”, 建筑承载着历史, 也承载着文化。远古先民曾选择天然的洞穴来居住, 虽也有人工的痕迹, 但还不能称之为建筑。建筑的形 成，在文明开始萌芽的时期。一个时代的历史全都可 以从建筑上看到, 而且往往比从文字历史中所看到的 更加直观、更加真实。建筑本身也是一种文化，是构 成文化的一部分, 是一种打上精神文化烙印的物质文 化。任何一种建筑背后都一定有文化的原因。住宅在 建筑史中出现最早, 随着历史的发展, 也是使用最多 的一种建筑类型, 现在各地留存的大都是明清时代的 住宅, 要说历史最久、在中国大地上覆盖最广的住宅 形式必是四合院住宅, 而北京四合院则堪称中国四合 院的代表。四合院建筑成为中国历史最悠久、应用范 围最广的住宅形式并不是一种偶然, 这其中就渗透着 中国人传统的空间意识, 渗透着中国人关于自然宇宙 的文化哲学思想和审美理念。 ${ }^{[2]}$ 本文将以北京四合院 空间布局为切入点, 讨论其建筑形式与中国古代哲学 自然观之间的联系, 阐述与之相关的中国古代哲学自 然观所包含的主要思想观点, 以期望通过了解建筑本 身加深理解中国文化思想并获得启示。

\section{2. 北京四合院的概况}

四合院的历史最早可以追溯到辽金时期, 当时的 契丹统治者在燕京城也就是现在的北京城内修建大 量的民居, 它们规整地排列在街巷的两边, 民居之间 自成院落, 这就成为四合院的雏形。而后发展到元代, 四合院初成气候, 每座四合院都有固定的规格、标准, 院落占地必须八亩, 南房北房以及东西厢房呈四面围 合状。到了明朝时期, 四合院的发展突破了元代的规 格限制, 变得更为灵活, 也更加适应居住的需求。清 朝是四合院建造的繁盛时期, 四合院的规模开始扩大, 有许多三进、四进合院甚至更大规模的合院出现, 清 政府还仿制四合院的格局打造了大批皇家园林供贵 族居住。现存的北京四合院则大多是明清时期留存下 来的, 也有部分民国时期建造的四合院, 建筑的形式 和功能大都固定, 结合历史记载和留存的合院建筑足 够梳理出北京四合院的建筑形制。

北京四合院是典型的木构架庭院式住宅形式, 它 的基本特征是四周用房屋或墙环筑，形成南北稍长、 左右对称，中间开阔的方形封闭式院落。 ${ }^{[3]}$ 最典型的 标准四合院是三进院, 分为前院、正院和后院。前院 与正院之间用垂花门分隔。近东南角的大门, 位于南 向的倒座房与垂花门围合成前院。正房坐北朝南, 以 游廊连接东西向厢房, 与垂花门围合成正院。位于北 向的后罩房则与正房围合成后院。合院没有楼房, 入 大门见影壁, 整个合院建筑以南北向延长线为中轴线, 正房位于中轴线上, 各单体建筑也都具有规定位置和 特定方位。正房一般为整个合院内最高的房屋, 有三 开间或五开间 (由四根柱子围成的空间称为 “间”), 正房左右有时搭建相对较矮的小房, 称为耳房。若正 房两侧各有一间耳房的，被称为 “明三暗五”，也就 是看上去是三个明间，但事实上共有五间房。北京四
合院在不同的历史时期或根据主人的意愿在设计形 式可能略有不同，但建筑形制的共性皆具有以上各点。

旧时的北京除了官式建筑如紫禁城、庙坛外, 就 是排列规整的百姓住宅, 这些被建造出来的建筑, 其 本身属于物质文化, 同时也被赋予了精神文化内核。 方方正正的四合院历经各朝各代留存至今, 已经不仅 仅是一种居住建筑，更蕴含着中华民族的精神内涵， 是中华文化思想的具体体现。

\section{3. 中国古代哲学自然观与北京四合院的关系}

中国古代哲学自然观是中国古人对自然的看法 和认识, 它有一个逐渐演化的过程。自然既存, 而后 有文明, 文明萌芽, 物质伴随着精神, 继而文化互成。 人类源于自然, 旧石器时代工具的产生是原始物质文 化的创造。原始先民的宗教艺术、崇拜观念等是原始 精神文化的体现。物质与精神合而成文明，立则文化 互成。中国古代哲学自然观也是一种文化产物, 它大 体经历了三种形态, 即神话形态、巫术形态和理性形 态。《礼记・祭法》: “山林川谷丘陵, 能出云, 为风 雨, 见怪物, 皆曰神。” 盘古开天辟地、女娲造人补 天等, 自然的一切都可以用神和神力来解释。神有神 力, 开天地, 造万物, 管时序, 运衡世界。到了殷商 时期, 古人开始相信有 “贞人” 可承接神意, 有《礼 记・表记》云: “殷人尊神, 率民以事神。”, “贞人” 可以通过占卜、堪與等巫术来接收神的命令用以指导 人的行为。巫术形态的自然观虽还是以神为本, 但已 初见古人对人与自然的思考。随后中国早期的一些圣 人等在此基础之上发展理性的关于自然的观点, 如汉 代董仲舒的天人感应论、北宋张载的天人合一思想等。

《易・贲卦》云: “天文也。文明以止, 人文也。观 乎天文, 以察时变; 观乎人文, 以化成天下。”古人 所说的 “天” 即为自然。

春秋战国时期之后, 中国哲学就出现了明确的天 人关系的思考, 也就是对人与自然关系的认识。中国 古代哲学自然观的体系内容也由此开始逐渐充实, 自 然观的发展从对自然本身的认识开始, 到对人与自然 关系的认识过渡，最终达到协调自然的目的。古人关 于天地生成的神创论到精气学说, 万物生成的神造论 到阴阳五行及八卦学说等都是对自然的认识, 随后开 始思考人在这天地万物中的位置, 即人与自然的关系。 中国古代关于自然的各种思想学说汇集成中国古代 哲学自然观, 尽管内容纷繁复杂, 但还是能从中提取 出中国古人对人与自然的关系的共性认识。中国古代 哲学自然观的核心内容就是人与自然的和谐统一。

北京四合院与中国古代哲学自然观并不是同一 时代的产物。从出现的历史时间上来看, 中国古人对 自然的认识要早得多, 住宅的出现更是基于古人最初 的自然观。北京四合院的形制发展过程中可以明显看 出建筑从最初的实用美到形式美的价值取向, 但都是 基于对自然的认识和在建筑中对人与自然关系的处 理。在人与自然和谐统一的追求上, 北京四合院可以 
说是臻于完美。笔者认为, 北京四合院的建筑设计受 到中国古代哲学自然观的影响, 并在建筑建造的实践 中丰富了中国古代哲学自然观的内涵。透过北京四合 院建筑本身, 观者可以从多角度多方面解读其中蕴涵 的中国古代哲学自然观的思想,而笔者对北京四合院 与中国古代哲学自然观关系的认识皆述于此, 以下将 对与北京四合院布局相关的中国古代哲学自然观的 部分内容在建筑中的具体体现进行阐释。

\section{4. 阴阳观在北京四合院中的体现}

中国古代哲学自然观中的一个重要的内容就是 阴阳观, 它对中国传统文化影响最深, 同时也是最具 神秘感的一个哲学范畴。春秋战国时期是中国哲学思 想发展的黄金时期, 诸子百家中的阴阳家尤擅长观测 阴阳, 其学术思想阴阳观盛行于天文、地理、医学、 农业等多个领域, 也渗透到建筑领域, 对中国传统建 筑产生深刻的影响。古人在建造时常把阴阳观的基本 观点和方法引入建筑构造, 与建筑发展积累的经验相 融合, 人们对建筑的追求不只是从实用性出发, 更是 在基础功能得到满足后提升到能否满足宜居条件。建 造开始更加关注人的身心、人与环境, 建筑在人与自 然的关系中逐渐扮演更重要的角色。

阴阳观是古人对世界本质和运行规律的一种猜 测, 古人通过研究阴阳的内涵及其运动变化规律, 来 解释世界万物万象的本原及其蕴涵的变化。阴阳最初 是根据太阳来判定的, 面对着太阳就是阳, 背对着太 阳就是阴。随着古人对事物认识的拓宽, 阴阳的含义 逐渐得到引申, 阴阳不再特指背向或面向太阳, 而变 成对自然界中事物或现象的类别的抽象概括。简单来 说, 阴阳指世界的两极, 世间万事万物都由阴阳相合 而成, 同时任何事物也都有阴阳这两个对立面, 如天 地、日月、男女、奇偶、上下, 等等。阴阳之间存在 对立统一、相互依存、相互作用、此消彼长、相互转 化等关系, 古人认为遵循阴阳法则可以使人与自然建 立连接, 对于自身大有禆益。在北京四合院建筑中, 阴阳的思想有着多种表现形式, 不考虑建筑功能、礼 制等单从建筑布局看其主要表现在空间、方位和数字 方面。

阴阳定四象空间。《易经》云: “是故, 易有太极, 是生两仪, 两仪生四象, 四象生八卦, 八卦定吉凶, 吉凶生大业。”天地之道, 以阴阳两仪化生万物, “四 象”即指太阳、太阴、少阳和少阴。太阳是阳中之阳, 太阴是阴中之阴, 少阳指阴中之阳, 少阴则是阳中之 阴。北京四合院以室外为阳, 室内为阴; 建筑为阳, 庭院为阴; 前院、正院为阳, 后院为阴。室外属阳中 之阳为太阳空间, 室内属阴中之阴为太阴空间, 檐廊 为处于室外作遮蔽用属于阳中之阴为少阴空间, 庭院 承接阳光属阴中之阳为少阳空间。前院、正院房屋一 般较高, 高为阳; 后院为女性居所, 房屋较矮, 矮为 阴。整个四合院空间皆是阴阳相合。

中国先民在建造房屋之前都会 “相其阴阳”, 这
就是在考虑方位对房屋建筑的影响。在方位观念中, 南为阳, 北为阴, 东为阳, 西为阴是最基本的要素。 四合院按南北中轴线对称建造, 各方位皆有房屋布置, 阴阳相成。受 “面南而治” 的影响, 君主坐北主阳, 合院正房坐北朝南, 其实也是由于中国位于地球北半 球, 房屋朝南可以在夏季避免阳光直射, 而在冬季可 以容纳更多的阳光同时避开西北寒风, 使室内阴阳调 和, 适应自然环境。

数字中的阴阳关系主要体现在奇数和偶数的关 系上。奇数为阳, 偶数为阴, 这一观念最直接地影响 着整个中国古代的建筑文化。中国的传统建筑大都是 奇数开间, 即三开间、五开间、七开间、九开间，少 有偶数开间。之所以采用奇数开间, 一方面是因为受 到阴阳观念的影响; 另一方面也是由中国传统建筑的 功能特点决定的。中国传统建筑的庭院组合是中轴对 称的, 所以中轴线上的主体建筑都是正中间进门, 奇 数开间, 门正好从中间的明间打开。如果是偶数开间 则正中间是柱子, 门就偏到一边了。北京四合院的正 房坐北朝南, 位于整个建筑的中轴线上, 一般为三开 间或五开间, 大抵就是受到数字方面阴阳观念的影响。

\section{5. 宇宙观在北京四合院中的体现}

中国古代哲学自然观中关于天地宇宙的形象表 述是 “天圆地方”，天是圆形的，地是方形的。“天圆 地方” 的认识来自于古代宇宙观其中之一的说法, 即 “盖天说”, 这是关于宇宙天地的一种较为原始朴素 的看法, 是中国先民直接观察自然并加以揣测后得到 的宇宙观。《晋书・天文志》中是这样描述的: “其言 天似盖笠, 地法覆槃, 天地各中高外下。……翢髀 家云: “天圆如张盖, 地方如棋局。天旁转如推磨而 左行, 日月右行, 随天左转。故日月实东行, 而天牵 之以西没。” ” 由此可以知道, “盖天说” 认为天是 圆形的, 就像一把大伞盖在大地上, 周而复始地转动, 而大地相是对静止的, 如一个方形的棋盘。“盖天说” 在发展过程中兼容其他学说的合理之处, 逐步完善自 身理论, 在先秦时代是影响最广泛的宇宙学说。秦汉 以来的建筑常延续 “法天象地” 的传统, 将天与地对 应起来, 以求达到天人合一的境界, 如北京的天坛、 地坛, 前者为圆形形制, 祭天; 后者为方形形制, 祭 地。这样建筑的形制就是 “象取天地” 的结果, 民居 住宅大都采用方形形制，直至明清时期，人们虽然对 宇宙有了新的认识, 但受传统礼制思想的影响, 中国 传统建筑的建造仍然延续着这样的形制, 而在民居中 最具代表性的就是北京四合院。

在北京四合院的营造格局中, 四周用房屋或墙环 筑, 正院中空, 就是基于中国古代哲学自然观中 “天 圆地方” 的宇宙观。四合院中的 “四” 为四方, 四面 建筑按南北中轴线对称修建, 成四方形, 表达“地方” 的意思; “合” 为闭合, 院落虽中空却闭合, 门窗皆 是开向院落, 表达 “天圆”之意。“天圆地方” 的宇 宙观是中国古人的时空观念, 是古人对自然规律的一 种认识, 将这种观念纳入建筑之中, 就体现了古人顺 
应自然规律，期望承接天地，达到天人合一的愿景。

\section{6. 风水观念在北京四合院中的体现}

风水是与中国古代建筑直接相关的一种思想、观 念或理论, 起源于中国古代哲学中关于“气”的思想。 风水大多是用来择定建筑的方位与空间, 主要关注人 与自然的关系问题, 它实际上也属于中国古代哲学自 然观。从古人对人与自然关系的认识来看, 风水思想 的内容主要分为两类,一类与居住环境相关，一类涉 及一些神秘且无法解释的事物, 关于后者本文不作赘 述。

古人认为一气生万物, 《庄子 - 知北游》云: “人 之生, 气之聚也。聚则为生, 散则为死。”, 所以聚生 气, 生万物。又晋朝郭璞所著《葬经》云: “气乘风 则散, 界水则止, 古人使聚之不散, 行之有止, 故谓 之 “风水””。气被风吹就会散掉, 碰到水就会停止运 动, 所以风水讲究 “藏风聚气”。所谓 “藏风聚气” 是指一种典型的风水格局, 也就是一个完整围合、向 心内聚的空间格局, 这种向心围合有利于阴阳二气和 合。

北京四合院的正房、东西厢房和倒座房位于 “四 正” 方位, 四角耳房、游廊以及大门位于 “四维” 方 位, 整体上构成一个完整而封闭的八卦空间, 最是适 合 “藏风聚气”。四合院的大门一般开东南门, 入门 有影壁, 根据八卦方位, 北为坎, 东南为巽, 坎水, 巽风, 东南门占风位, 可以引进东南暖风, 挡住西北 的寒风, 这种布局也称为 “坎宅巽门”, 影壁则有助 于气流流动, 起到聚气的效果。从地理位置上来看, 中国大部分位于地球的北半球, 北京地处我国北方, 气候特征为冬季多西北风, 温湿度低; 夏季多南风, 温湿度都高。地球公转北半球受阳从南面射入, 因此 四合院坐北朝南阳光充沛，四面围合同时抵挡了寒风。 风水观念在中国文化传承上一直颇受争议, 但破除封 建迷信后来看, 风水本质上也是中国古人在建筑规划 时, 期望建筑、人与自然达到和谐统一所总结出来的 一些规律，值得辩证看待。

\section{7. 结论}

在中国大地上, 文明起源于黄河、长江流域, 这 里的自然条件很好, 所以农业发达, 能够使中国人自 给自足。在这种生存环境下, 形成了中国人寻求自然 庇护, 顺应自然的态度。中国古代诸子百家, 各种哲 学流派的思想各有不同, 但在人与自然的关系问题上, 却几乎达成了一致。儒家的 “天人合一”、道家的 “道 法自然”, 以及哲学中的阴阳学说、医学中的经络理 气、建筑中的风水观念等等, 都表达出对人与自然和 谐统一的追求。这种哲学思想影响了中国传统建筑的 构造, 更成为传统民居建筑形制形成的重要基础。

北京四合院作为中国古代民居建筑的代表，它的 建筑布局不但符合人们生存的实用性, 也让生活在合
院里的人们得到精神上的满足。这部木结构架成的历 史，裹挟着自然的清风，在人们眼前显现，诉说着中 国思想文化独有的鬼韦力。人类的文明与自然总是相向 而行的, 这样我们便不单单只在自然中建起一间宫室, 一个家, 同时也在建筑中感受到大自然的存在, 达到 人与自然和谐统一的至高境界。虽说古人在几千年之 前开始建造房屋时可能并没有刻意在设计上表现对 大自然的深厚情感，但在其发展过程中伴随着思想的 迭代, 并在历史的推进中逐渐形成了一种文化, 而留 存下来的古建筑待后人透过建筑本身去深入理解其 中蕴涵的思想和文化。

\section{REFERENCES}

[1] Zhang, Y.K., (2004) The Origin Mechanism of Chinese Traditional Courtyard Architecture. Journal of Tianjin University (Social Sciences), 02: $101-105$.

[2] Fu, H., (2014) The Behavior-oriented Implication in the Space of the Courtyard. Journal of Research on Design Art, 06: 88-93.

[3] Liu, D.Z. (2003) Overview of Chinese Housing. Baihua Art Publishing, Tianjin.

[4] Xiao, H.N., (2005) The Aesthetic Implication of Chinese Traditional Architecture Beijing Courtyard. Central South University.

[5] Sha, R., (1997) The Natural View of Chinese Traditional Dwelling Architecture Culture and Its Origin. Journal of Human Geography, 03: 29-33.

[6] Zhang, D.N., Fang, K.L., (2004) An Introduction to Chinese Culture. Beijing Normal University Press, Beijing.

[7] Tan, J.Y., (2018) A New Exploration of the Inheritance of Chinese Excellent Traditional Culture--a Review of Four Seasons of Chinese Culture Series Edited by Professor Ma Xin. Shandong Social Sciences, No.269(01):194.

[8] Liu, S., (2014) The Civilization of Construction--Chinese Traditional Culture and Traditional Architecture. Tsinghua University Press, Beijing.

[9] Fan, X., (2013) On the Architectural Culture of Beijing Quadrangle Courtyard. Journal of Shanxi Architecture, 39(32):6-7.

[10] Mu, Y.S., (2012) Research on the Formation Process and Spatial Composition of Chinese Courtyard Houses--Focusing on Beijing Quadrangle Courtyard. Journal of Value Engineering, 31(03):51-53.

[11] He, J., (2011) Discussion on the Origin of Ecological Architecture from the Angle of 
Human and Nature. Journal of Master, 24:95-96.

[12] Feng, C.P., (2011) Analysis of Natural View of Architectural Environment in Chinese Traditional Culture. Journal of Doors \& Windows, 08:340-341.

[13] Liu, T.H., (1994) Yin-yang Culture and Traditional Architectural Culture. Journal of Social Sciences, 09:39-43. 